\title{
Surface characterization of plasma treated polymers for applications as biocompatible carriers
}

\author{
P. Slepička ${ }^{1 *}$, N. Slepičková Kasálková1 ${ }^{1}$ E. Stránská ${ }^{1}$, L. Bačáková ${ }^{2}$, V. Švorčík ${ }^{1}$ \\ ${ }^{1}$ Department of Solid State Engineering, Institute of Chemical Technology, 16628 Prague, Czech Republic \\ ${ }^{2}$ Institute of Physiology, Academy of Sciences of The Czech Republic, 14220 Prague, Czech Republic
}

Received 22 December 2012; accepted in revised form 25 February 2013

\begin{abstract}
The objective of this work was to determine surface properties of polymer surfaces after plasma treatment with the aim of further cytocompatibility tests. Examined polymers were poly(ethyleneterephthalate) (PET), high-density polyethylene (HDPE), poly(tetrafluoro-ethylene) (PTFE) and poly(L-lactic acid) (PLLA). Goniometry has shown that the plasma treatment was immediately followed by a sharp decrease of contact angle of the surface. In the course of ageing the contact angle increased due to the reorientation of polar groups into the surface layer of polymer. Ablation of polymer surfaces was observed during the degradation. Decrease of weight of polymer samples was measured by gravimetry. Surface morphology and roughness was studied by atomic force microscopy (AFM). The PLLA samples exhibited saturation of wettability (aged surface) after approximately 100 hours, while the PET and PTFE achieved constant values of contact angle after 336 hours. Irradiation by plasma leads to polymer ablation, the highest mass loss being observed for PLLA. The changes in the surface roughness and morphology were observed, a lamellar structure being induced on PTFE. Selected polymer samples were seeded with VSMC (vascular smooth muscle cells) and the adhesion and proliferation of cells was studied. It was proved that certain combination of input treatment parameters led to improvement of polymer cytocompatibility. The plasma exposure was confirmed to significantly improve the PTFE biocompatibility.
\end{abstract}

Keywords: nanomaterials, biopolymers, plasma processing, surface morphology, biocompatibility

\section{Introduction}

The surface modification of solid substrates by plasma exposure is mostly used for etching, crosslinking, surface activation (radical formation) and as pre-deposition process. The modification processes is not restricted to plasma irradiation, since the performed air exposure also leads to significant surface changes. The process of aging is characterized by significant surface chemistry changes, the formation of new functional groups, branching, crosslinking and low molecular species formation [1-3]. Plasma can be described as an energetic medium composed of electrons, positively and negatively charged ions, radicals, atoms and molecules, which are obtained by using outer energetic source [4] and can be also quantitatively characterized. Plasma sources are characterized by electron density, uniformity and type of energetic source. Mostly used sources are RF (radio-frequency) or microwave excitation sources. The first group of reactions involves the reaction of surface with active species contained in plasma (oxidation, scissoring), the second group is the restructuring of the surface due to free radicals creation (degradation, oxygen incorporation) [5]. Polymer matrix can be also improved by various type of particles, e.g. graphite nanoplatelets [6]. In case of reactive plasma modification the electrical field causes acceleration of free electrons

\footnotetext{
*Corresponding author, e-mail: petr.slepicka@vscht.cz

(C) BME-PT
} 
and the kinetic energy of electrons is sufficiently high to cause ionization, fragmentation and excitation processes of gas molecules. Thus the activated atoms and molecules generate a highly reactive gas mixture, which is able to react with the exposed surface. Plasma exposure causes four main effects that occur during the plasma modification process itself: (i) surface cleaning, (ii) surface ablation or etching, (iii) cross-linking and (iv) modification of chemical properties.

The velocity of electrons is typically much higher than ion velocity. Exposure to plasma discharge can lead to the introduction of chemical functionalities, the nature of the functionalities highly depending on the chemical composition of the biomaterial and the process gas $[7,8]$. The depth of modification arises from plasma power and exposure time. Typically it is few hundred of Ångströms (determined by RBS, Rutherford backscattering) and the modified layer can be measured e.g. with RBS and XPS (X-ray photoelectron spectroscopy) method. Øiseth [1] has stated that the depth probed by the instrument can reach approximately $10 \mathrm{~nm}$. A gradient of incorporated oxygen into polymer surface can be present. Surface modifications induced by plasma processes can be mainly divided into three categories: etching, functionalization and deposition. The volatile species can be created during plasma exposure. The commonly used gases for plasma treatments are argon or nitrogen [1-3,5]. The degree (efficiency) of etching during plasma processes depends on the density of active species and intensity (power) of ion bombardment towards the surface. The etching degree also strongly depends on polymer temperature, i.e. the temperature of base table [6]. Plasma etching can be performed also on metals, semiconductors which in combination with polymer's etching can find a variety of applications in electronics or biotechnological engineering.

The plasma exposure induces physico-chemical changes of the polymeric surface. The interaction of polymer surface with plasma can cause hydrogen separation from polymeric chains and free radical creation. Radicals are created due to $\mathrm{Ar}^{+}$or electron impacts, the $\mathrm{C}-\mathrm{C}$ and $\mathrm{C}-\mathrm{H}$ bonds being disrupted [6]. With the CASING phenomenon (Cross-linking by activated species of inert gases) radicals interact with each other [4]. Grace and Gerenser [9] introduced PE, PP, PS surface modifications induced by a plasma only supplied with a rare gas (and so without any reactive gas such as $\mathrm{O}_{2}$ ) that do not provide new functional groups on the PE, PP or PS surface during exposure in the chamber, the groups are mainly created due to exposure to the modified surface to air. The radicals created by plasma activation can interact with oxygen or nitrogen from air and thus the new functional groups may be incorporated into the polymer surface $[1,4,6]$. From some polymers containing oxygen (e.g. PET, PC or PMMA) the $\mathrm{CO}$ or $\mathrm{CO}_{2}$ groups can be released. The $\mathrm{H}_{2} \mathrm{O}$ plasma can be used for incorporation of hydroxyl groups on the polymer surface. The oxidation reaction plays mostly the main role [9]. Plasma containing nitrogen $\left(\mathrm{N}_{2}\right.$ or $\mathrm{NH}_{3}$ plasma) improves wettability, biocompatibility and printability of polymeric surfaces.

The physico-chemical changes of selected polymer surfaces (PET, HDPE, PTFE, PLLA) induced by argon plasma are introduced in this paper. The surface contact angle and aging studies were performed. The influence of plasma interaction on surface morphology is described. Physico-chemical changes were characterized in connection to the cell adhesion and proliferation on selected substrate.

\section{Materials and methods}

\subsection{Materials and plasma treatment}

Polyethyleneterephthalate (PET, Goodfellow Cambridge Ltd., Cambridge, Great Britain, $1.4 \mathrm{~g} \cdot \mathrm{cm}^{-3}$, $50 \mu \mathrm{m}$ ), high-density polyethylene (HDPE, Granitol Moravsky Beroun a.s. Czech Republic, $0.95 \mathrm{~g} \cdot \mathrm{cm}^{-3}, \quad 50 \mu \mathrm{m}$ ), (polytetrafluoroethylene (PTFE, Goodfellow Cambridge Ltd., Cambridge, Great Britain, $\left.2.2 \mathrm{~g} \cdot \mathrm{cm}^{-3}, 50 \mu \mathrm{m}\right)$ and biopolymer poly(L-lactic acid) (PLLA, Goodfellow Cambridge Ltd., Cambridge, Great Britain, $1.25 \mathrm{~g} \cdot \mathrm{cm}^{-3}, 50 \mu \mathrm{m}$ ) were used for the experiments. The samples were modified in diode plasma discharge on Balzers SCD 050 device for 0-400 s (BalTec Maschinenbau AG, Pfäffikon, Switzerland), using DC Ar plasma (gas purity was $99.997 \%$, power 5 and $10 \mathrm{~W})$. Process parameters were: Ar flow $0.3 \mathrm{~L} \cdot \mathrm{s}^{-1}$, Ar pressure $10 \mathrm{~Pa}$, electrode area $48 \mathrm{~cm}^{2}$, the interelectrode distance of $50 \mathrm{~mm}$, chamber volume $1000 \mathrm{~cm}^{3}$. The sample is located on the cathode during the modification and its position is perpendicular to the flow. 


\subsection{Measurement techniques}

Contact angles were determined by goniometry with static water drop method. The Sessile Drop Technique was used for the characterization. The measurements of the water contact angles (error $\pm 5 \%$ ) were performed using distilled water on 10 different positions using the Surface Energy Evaluation System (Advex Instruments, Brno, Czech Republic).

Surface morphology and roughness of the pristine and modified polymer samples were examined by the AFM technique using a Bruker Corporation CP-II setup (Santa Barbara, CA, USA) device working in tapping mode. A Si probe RTESPA-CP, with the spring constant $20-80 \mathrm{~N} \cdot \mathrm{m}^{-1}$, was used. The mean roughness value $\left(R_{\mathrm{a}}\right)$ represents the arithmetic average of the deviations from the centre plane of the sample. We have performed the AFM measurements on 3 different places for each modification.

The gravimetric analysis of the ablated surface layer after plasma treatment was performed using an ultra micro-balance Mettler Toledo UMX2 (Metler Toledo LLC, Columbus, USA). The thickness of the ablated layer was converted from the change in weight of 8 samples of same surface area before and after the treatment using tabulated polymer density. A depolarization high-frequency gate was used to achieve surface discharge in order to minimize the influence of surface electrostatic charge on the measurement with Mettler Toledo UMX2.

\subsection{Cell culture, adhesion and proliferation}

For cell culture in vitro experiments, 4 samples from each modification and for each time interval were used. The samples were sterilized for $1 \mathrm{~h}$ in ethanol (75\%), air-dried, inserted into polystyrene 12-well plates (TPP, Switzerland; well diameter $20 \mathrm{~mm}$ ) and seeded with vascular smooth muscle cells (VSMCs) derived from the rat aorta by an explantation method [10]. The procedure of cell's seeding is well described in [3]. The cell proliferation activity was estimated from the increase in the cell numbers achieved on the $1^{\text {st }}, 3^{\text {rd }}$ and $7^{\text {th }}$ days after seeding [3]. The number and the morphology of the cells on the sample surface were then evaluated on microphotographs taken under an Olympus IX 51 microscope (Olympus, Prague, Czech Republic). The number of adhered and proliferated cells was determined from the 3 samples. 1 sample from the each modification was used for determination of the viability of the cells [3].

\section{Results and discussion}

\subsection{Contact angle measurement and surface aging}

Contact angles immediately after treatment were measured on polymers modified with 5 and $10 \mathrm{~W}$ and exposure time 10-240 s. The dependence of contact angle on exposure time for polymers is introduced in Figure 1. The PTFE exhibited the smaller decrease of contact angle. From value for pristine PTFE $\left(108.7 \pm 3.8^{\circ}\right)$ a decrease to $\left(83.7 \pm 3.8^{\circ}\right)$ for treated PTFE with $10 \mathrm{~W}$ and $10 \mathrm{~s}$ and a decrease down to $\left(45.6 \pm 3.1^{\circ}\right)$ for PTFE treated with $10 \mathrm{~W}$ and $240 \mathrm{~s}$ were observed. The higher the plasma power applied the more pronounced decrease of contact angle was observed. Exposure to plasma leads to a partial defluorination by $-\mathrm{C}-\mathrm{F}$ bond scission or polymer chain breakage. The $-\dot{\mathrm{C}}-\mathrm{F}$ may arise from the ion interaction, which can react with other radical on polymer surface, air oxygen, $-\mathrm{C}=\mathrm{C}-$ bonds may be created on the plasma activated surface [11]. The PTFE surface exhibits lower

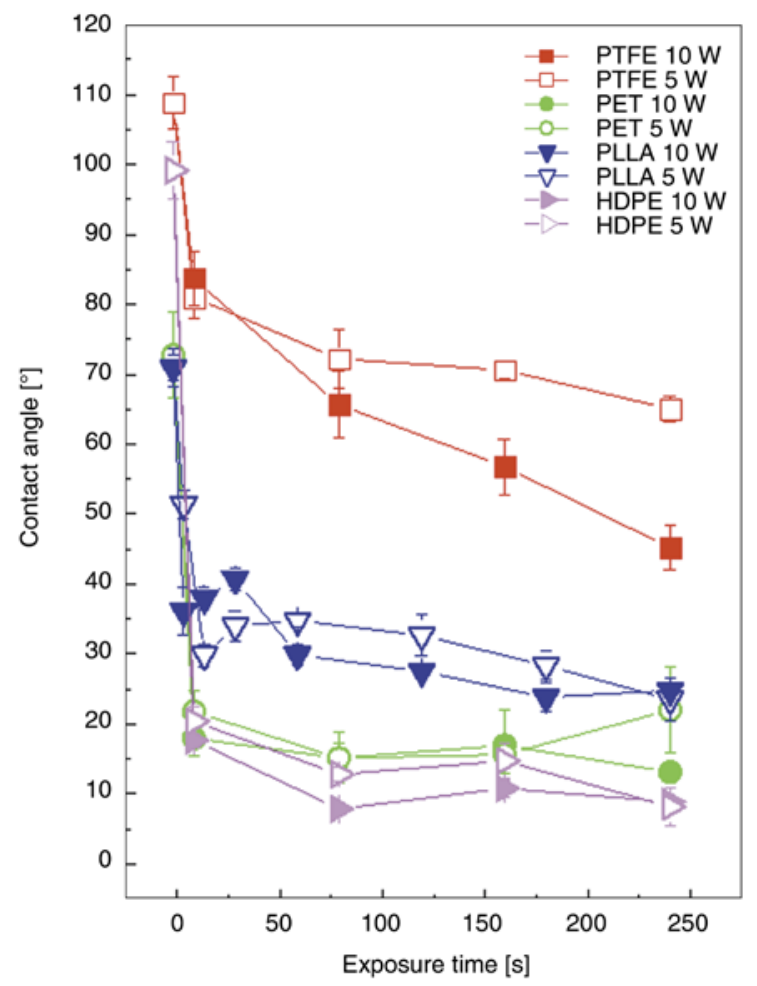

Figure 1. Dependence of the contact angle on the plasma exposure time for plasma-treated PET, HDPE, PTFE and PLLA. The exposure powers were 5 and $10 \mathrm{~W}$ 
free radical count available for reaction with oxygen or nitrogen in comparison to other polymers [11]. The crystallinity of polymer may also be affected [12]. The incorporation of the previously mentioned species into polymer surfaces may not be as progressive as for PET or PLLA, and the wettability is lower in comparison to above spoken polymers.

PET exhibited significantly higher decrease of contact angle due to treatment in comparison to PTFE. The higher decrease was observed for samples treated with $10 \mathrm{~W}$, the contact angle decreased from $\left(71.1 \pm 3.1^{\circ}\right)$ to $\left(24.1 \pm 3.1^{\circ}\right)$. There is also an apparent interval of non-regular decrease and increase of contact angle for shorter exposure times, which is caused by the ablation of polymer surface at the beginning of the modification, where the contact angle for PET decreased from $\left(72.9 \pm 6.1^{\circ}\right)$ for pristine PET to minimal value of $\left(18.6 \pm 2.4^{\circ}\right)$ for plasma power $10 \mathrm{~W}$. The decrease of contact angle is connected to changes in surface chemistry and indicated increase of surface polarity. The interaction of PET [13] with plasma leads to the $-\mathrm{C}-\mathrm{O}-$ bond breakage in ester groups the polymer chain being disrupted. The lower plasma power led to lower decrease of contact angle for all studied polymers (PET, HDPE, PTFE, PLLA). This phenomenon is probably caused by lower kinetic energy, charge and density of impacted argon ions towards to polymer surface. The interaction of plasma with polymer surface, e.g. polyethylene can induce several changes in surface wettability but also morphology [14-16] as well as deposition of biologically active compounds $[17,18]$. The significant changes of polymer surface properties (both morphology and contact angle) due to modification by application of $\mathrm{He}^{+} \mathrm{N}_{2}$ dielectric barrier discharge was observed by Borcia et al. [19]. It was also shown that at low energy densities the plasma treatment at medium pressure is more energy-efficient in incorporating oxygen functionalities than plasma treatment at atmospheric pressure [20]. At elevated pressure also the changes of applied gas (helium vs. argon) plays an important role [21,22]. Several reviews about plasma treatment of polymers for biomedical applications have been published recently [23-25]. Biopolymers have been also studied [26].

For HDPE the contact angle decreased from the original value $\left(99.1 \pm 4.1^{\circ}\right)$ down to $\left(18.3 \pm 1.0^{\circ}\right)$ for polymer treated for $10 \mathrm{~s}$ and $10 \mathrm{~W}$. With higher exposure time the contact angle further decreases down to $\left(9.6 \pm 0.9^{\circ}\right)$ for HDPE modified with $10 \mathrm{~W}$ and $240 \mathrm{~s}$. On the HDPE surface the three types of radicals can be created: alkyl, allyl and DBS (dangling bond sites) with different stabilities [1]. The functional radicals cause the creation of double bonds in the polymeric layer and forming of oxidized functional groups on the surface. These groups are created by the interaction of activated surface with gases from the atmosphere during the modification or, more often after the procedure [1].

The aging of polymer was determined after polymer surface modification and during this period the contact angle stabilization was achieved for the studied polymers. The data for selected polymers aging are introduced in Figures $2 \mathrm{a}-2 \mathrm{c}$.

The aging of HDPE surface is introduced in Figure 2a. The surface underwent aging process finishing after 384 hours. The exception was the sample modified with highest exposure time, where a slight increase of contact angle was observed. The values of contact angles after the aging period (384 hours) remained constant above $\left(99.1 \pm 4.1^{\circ}\right)$, the exception was the sample modified with $10 \mathrm{~s}$. This sample after the aging process exhibited significantly lower value close to $80^{\circ}$, the value being lower than that of pristine HDPE. We suppose that this phenomenon was caused by the amount of oxygenated groups on the modified surface and more importantly by the amount of oxygenated groups which rotated during the aging process into the polymer bulk (this phenomena is more pronounced for the HDPE modified with $10 \mathrm{~s}$ ).

In case of PET the $\mathrm{CO}$ and $\mathrm{CO}_{2}$ release during the polymer surface aging can occur [27]. The benzene core is not attacked. The free radicals are created during the modification process and the oxygenated groups $(-\mathrm{OH},-\mathrm{COOH})$ are incorporated into the polymer surface partially during the modification process and immediately after the contact of modified samples with the oxygen in air. The multiple bonds are also created and this may result in polymer casing formation [27]. From Figure $2 b$ it is obvious, that during aging process the contact angle increases for all applied exposure times, the constant value being achieved approximately after 336 hours. The value of aged surface is higher than value for pristine PET $\left(72.9 \pm 6.1^{\circ}\right)$. The exception is sample 

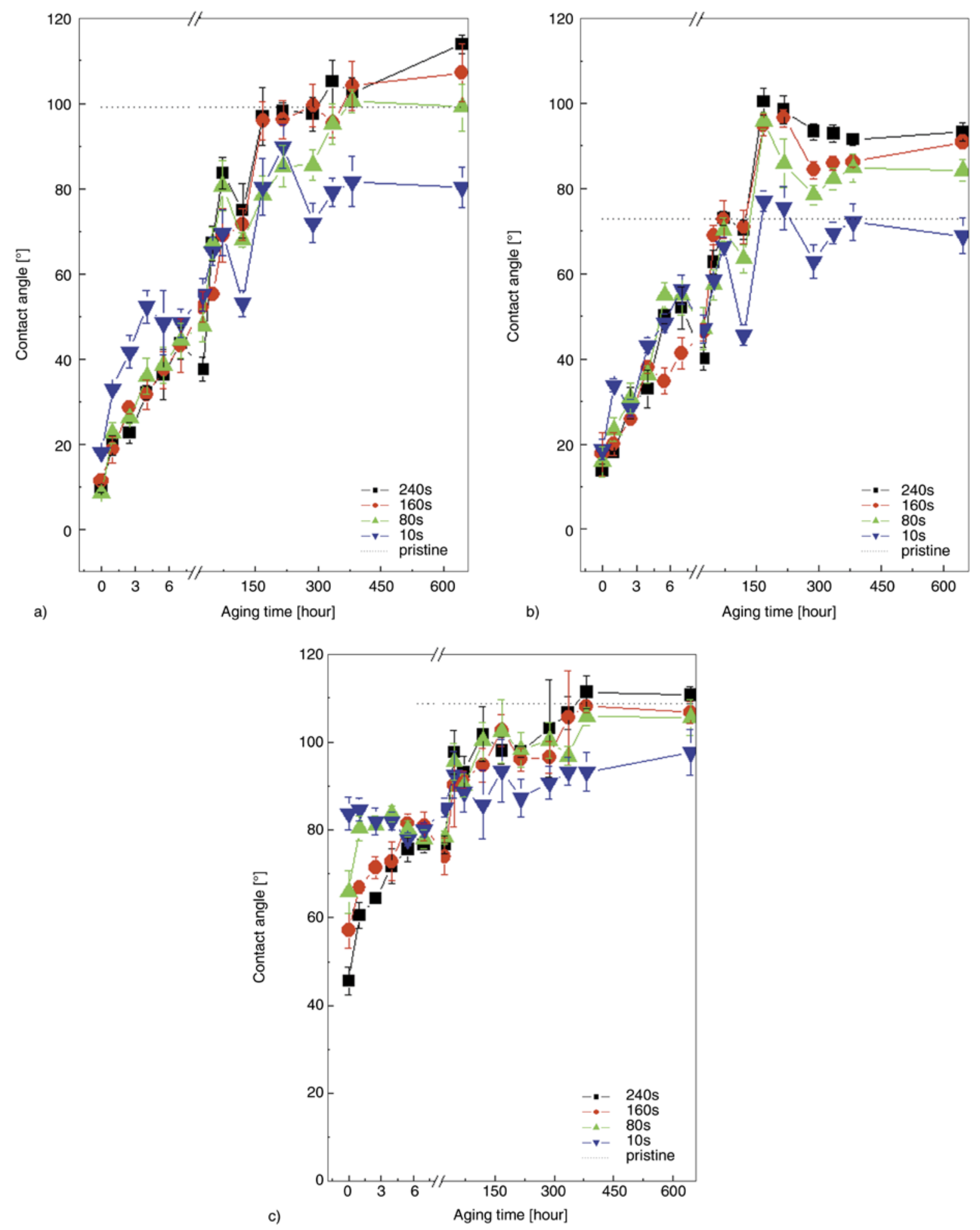

Figure 2. The dependence of contact angle of modified HDPE (a), PET (b) and PTFE (c) on aging time for applied plasma power $10 \mathrm{~W}$

treated with $10 \mathrm{~s}$, where this value is approximately similar. The values during aging process are lower for the sample treated only with $10 \mathrm{~s}$ during whole aging period in comparison to 80,160 and $240 \mathrm{~s}$.

The PTFE aging process is accomplished with $-\dot{\mathrm{C}}-\mathrm{F}$ radicals creation induced by interaction with $\mathrm{Ar}^{+}$ ions. The consequent reaction with air oxygen may occur as well as relaxation of polymer chain, where the polar groups are rotating into the polymer surface and also the diffusion of non-modified segments towards to the very surface may occur [28]. From Figure 2c it can be concluded, that the contact 


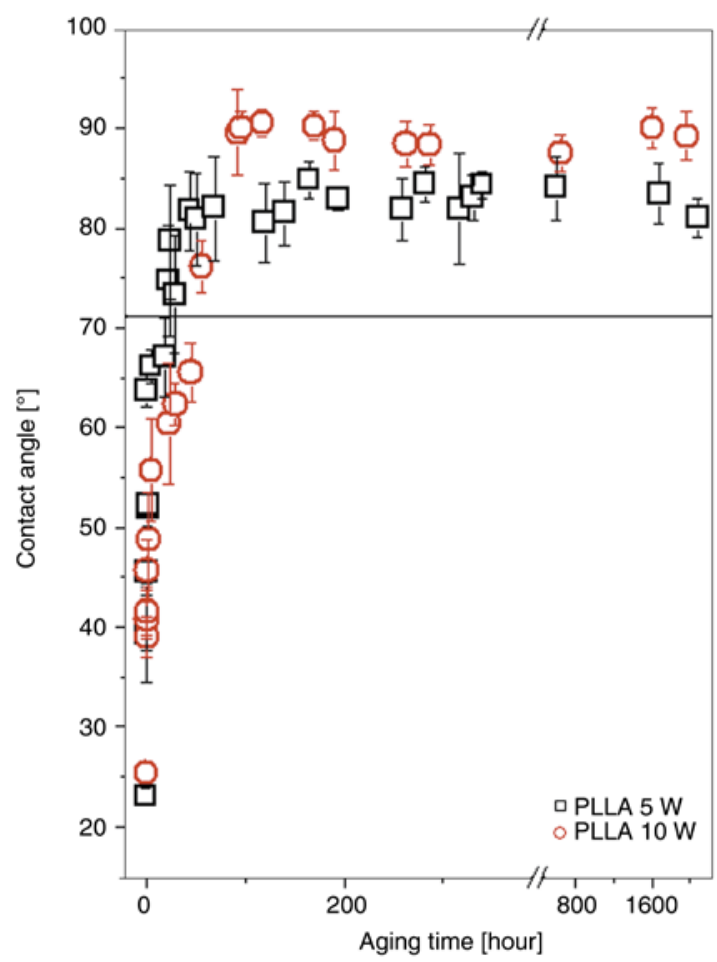

Figure 3. Dependence of the contact angle of PLLA on sample aging time. The plasma discharge powers were 5 and $10 \mathrm{~W}$. Contact angle of pristine polymer is shown by solid line

angle of PTFE surface becomes constant after approximately 336 hours. The values stabilize at contact angles smaller than value of pristine PTFE $\left(108.7 \pm 3.8^{\circ}\right)$. The exception was found for PTFE activated with $10 \mathrm{~W}$ and $240 \mathrm{~s}$, the contact angle being stabilized slightly above the value of pristine PTFE.

The use of lower plasma power $(5 \mathrm{~W})$ had no significant effect of the aging behaviour of the above spoken polymer substrates. The contact angle achieved a constant value after approximately similar interval as those exposed to $10 \mathrm{~W}$ (i.e. aging time 336 hours and higher). For the demonstration, the aging of PLLA samples treated with 5 and $10 \mathrm{~W}(240 \mathrm{~s})$ is introduced in Figure 3. Such treatment parameter (time $240 \mathrm{~s}$ ) was chosen for aging study (and introduction of different plasma power influence) since it exhibited the most pronounced decrease of the contact angle immediately after the modification. For PLLA the contact angle increases rapidly with increasing aging time and after about 100 hours of aging it achieves a saturation at about $83^{\circ}$ and $87^{\circ}$ for 5 and $10 \mathrm{~W}$ discharge power respectively (compare with $71.1^{\circ}$ of pristine PLLA).

\subsection{Surface morphology and mass loss (ablation)}

The surface morphology of pristine polymers and plasma treated polymers are introduced in Figure 4. The plasma activation leads to an increase in the surface roughness of PET (Figures 4a, 4b). The granular structure of PET is more pronounced after plasma modification. The analysis of HDPE surface morphology has shown (Figures 4c, 4d) that due to plasma activation the HDPE surface morphology significantly changes, the roughness being slightly increased. On the contrary, plasma modification of PTFE does not significantly change the surface roughness, the surface structure being significantly altered (Figures $4 \mathrm{e}, 4 \mathrm{f}$ ). The pronounced lamellar structure was observed on plasma activated PTFE. The effect of plasma activation was also observed for PLLA foil. For the sake of clarity the scan $10 \times 10$ was chosen, so that the changes of PLLA foil could be clearly visible. The pristine PLLA exhibits the surface morphology with no obvious surface irregularities and surface roughness $R_{\mathrm{a}}=7.0 \mathrm{~nm}$ (Figure $4 \mathrm{~g}, 4 \mathrm{~h}$ ). As a result of plasma irradiation the surface roughness dramatically increases and sharp fragments appear on the modified surface. During the ablation (see later), the amorphous phase is preferentially ablated while the crystalline amount of PLLA surface being revealed.

The ablation during the plasma treatment has been studied by gravimetry. The ablation mass loss of polymer was consecutively converted to polymer thickness. The mass losses determined after plasma treatment (power $10 \mathrm{~W}$, time $240 \mathrm{~s}$ ) are introduced in Figure 5. With increasing exposure time the higher ablation loss was apparent. The highest ablation loss was observed for PLLA. The thickness of ablated material was $73 \mathrm{~nm}$ (see Figure 5). The mass loss for the same treatment parameters resulted to ablation loss approximately $39 \mathrm{~nm}$ PTFE and $27 \mathrm{~nm}$ for PET. The lowest ablation loss has been observed for HDPE. It can be concluded, that the highest ablation due to Ar plasma (the lowest resistance to plasma discharge) exhibits biodegradable polymer PLLA. 

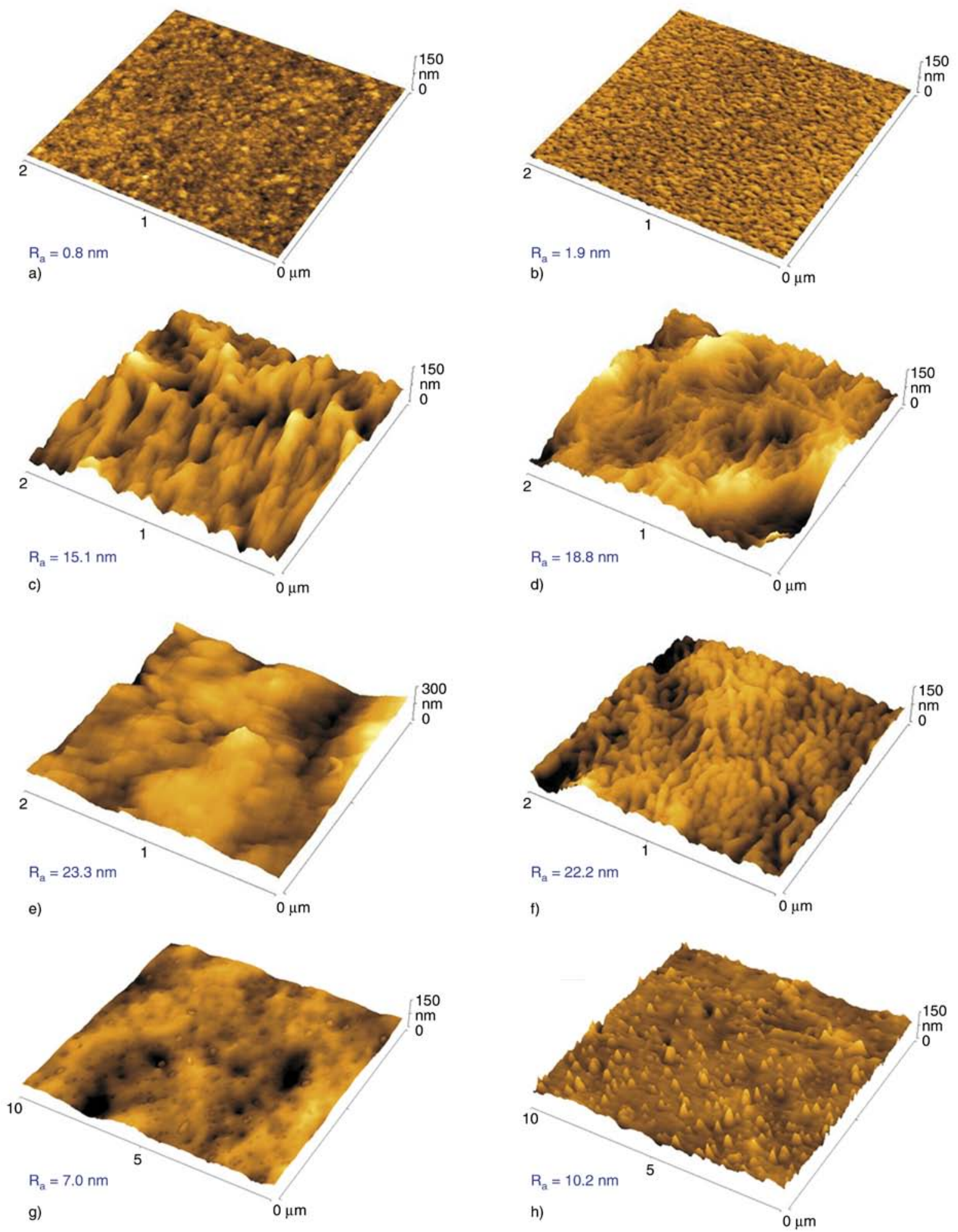

Figure 4. AFM images: pristine PET (a), PET modified with $10 \mathrm{~W}$ and $240 \mathrm{~s}$ (b), pristine HDPE (c), HDPE modified with $10 \mathrm{~W}$ and $240 \mathrm{~s}$ (d), pristine PTFE (e), PTFE modified with $10 \mathrm{~W}$ and $240 \mathrm{~s}$ (f), pristine PLLA (g), PLLA modified with $10 \mathrm{~W}$ and $240 \mathrm{~s}(\mathrm{~h}) . R_{\mathrm{a}}$ is the average surface roughness in $\mathrm{nm}$.

\subsection{Cytocompatibility}

Since our earlier studies have been focused on the biocompatibility of HDPE and PLLA (modified under different conditions) we chose for the cell adhesion and proliferation tests PTFE substrate. The PTFE substrate was modified with 5 and $10 \mathrm{~W}$ (240 s). The former one ( $5 \mathrm{~W}$ ) will be discussed further, the values being similar in a trend to that of 


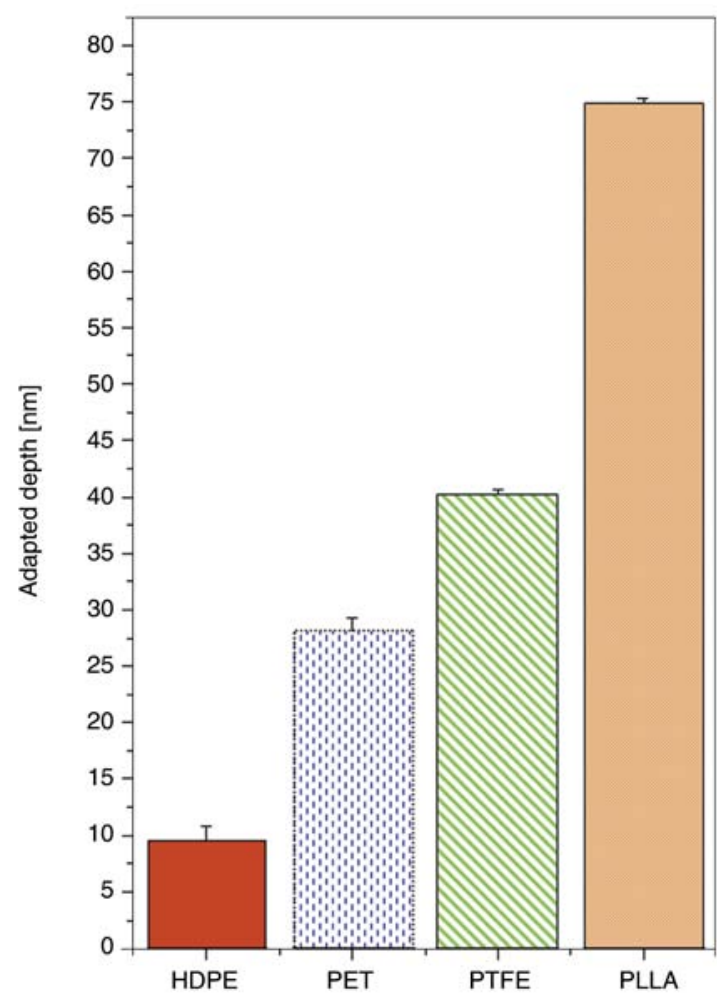

Figure 5. The ablated thickness of polymer (HDPE, PET, PTFE, PLLA) for plasma treatment power $10 \mathrm{~W}$, exposure time $240 \mathrm{~s}$

higher plasma power. The initial seeding number of cells $\left(17000 \mathrm{~cm}^{-2}\right)$ was followed by the decrease up to $6700 \mathrm{cells} \cdot \mathrm{cm}^{-2}(\mathrm{PTFE} / 5 \mathrm{~W})$ due to initial process of cell adhesion, where the cell's dying takes place. The cells which successfully survive and adhere on the PTFE surface further proliferate. The increase up to $15000 \mathrm{~cm}^{-2}$ was observed after 48 hours on the plasma activated PTFE. The lowest number of adhered cells was observed on pristine PTFE after 24 and 48 hours from seeding. Third day after seeding a sharp increase of cell number was observed on plasma exposed PTFE (up to 65000 cells $\cdot \mathrm{cm}^{-2}$ ), while the pristine PTFE exhibited cell numbers below 3000 cells $\cdot \mathrm{cm}^{-2}$. After 7 days from seeding the cell number on plasma modified PTFE was further doubled up to numbers exceeding 100000 cells $\cdot \mathrm{cm}^{-2}$. The appropriate photographs of the pristine PTFE and plasma activated PTFE surface with adhered and proliferated VSMC cells is introduced in Figure 6. The plasma exposure was confirmed to be significantly improving tool for the PTFE biocompatibility.

\section{Conclusions}

Physico-chemical properties of plasma-treated PET, HDPE, PTFE and PLLA samples were determined. Plasma treatment leads to dramatic changes in the surface polarity (wettability). The wettability increase caused by plasma activation was dependent on plasma power and exposure time, the most pronounced changes were observed for $10 \mathrm{~W}$ and $240 \mathrm{~s}$. The PLLA samples exhibited saturation of wettability (aged surface) after approximately 100 hours, while the PET and PTFE achieved constant values of contact angle after 336 hours. Irradiation by plasma leads to polymer ablation, the highest mass loss being observed for PLLA. The changes in the surface roughness and morphology are observed, the lamellar structure being induced on PTFE. The plasma exposure was confirmed to be a powerful tool for enhancing PTFE biocompatibility.

\section{Acknowledgements}

This work was supported by the GACR under project P108/12/G108.

Abbreviations

\begin{tabular}{|c|c|}
\hline AFM & atomic force microscopy \\
\hline $\mathrm{Ar}$ & argon \\
\hline CASING & cross-linking by activated species of inert gases \\
\hline $\mathrm{CO}$ & carbon oxide \\
\hline $\mathrm{CO}_{2}$ & carbon dioxide \\
\hline $\mathrm{COOH}$ & carboxyl group \\
\hline $\mathrm{DC}$ & direct current \\
\hline $\mathrm{H}_{2} \mathrm{O}$ & water \\
\hline HDPE & high density polyethylene \\
\hline $\mathrm{He}^{+}$ & helium cation \\
\hline $\mathrm{N}_{2}$ & nitrogen \\
\hline $\mathrm{NH}_{3}$ & ammonia \\
\hline $\mathrm{OH}$ & hydroxyl group \\
\hline $\mathrm{PC}$ & polycarbonate \\
\hline $\mathrm{PE}$ & polyethylene \\
\hline PET & poly(ethylene terephthalate) \\
\hline PLLA & poly(L-lactic acid) \\
\hline PMMA & poly(methyl methacrylate) \\
\hline $\mathrm{PP}$ & polypropylene \\
\hline PS & polystyrene \\
\hline PTFE & poly(tetrafluoro ethylene) \\
\hline$R_{\mathrm{a}}$ & arithmetic roughness \\
\hline RBS & Rutherford backscattering spectrometry \\
\hline RF & radio-frequency \\
\hline $\mathrm{Si}$ & silicon \\
\hline XPS & X-ray photoelectron spectroscopy \\
\hline VSMC & vascular smooth muscle cells \\
\hline
\end{tabular}



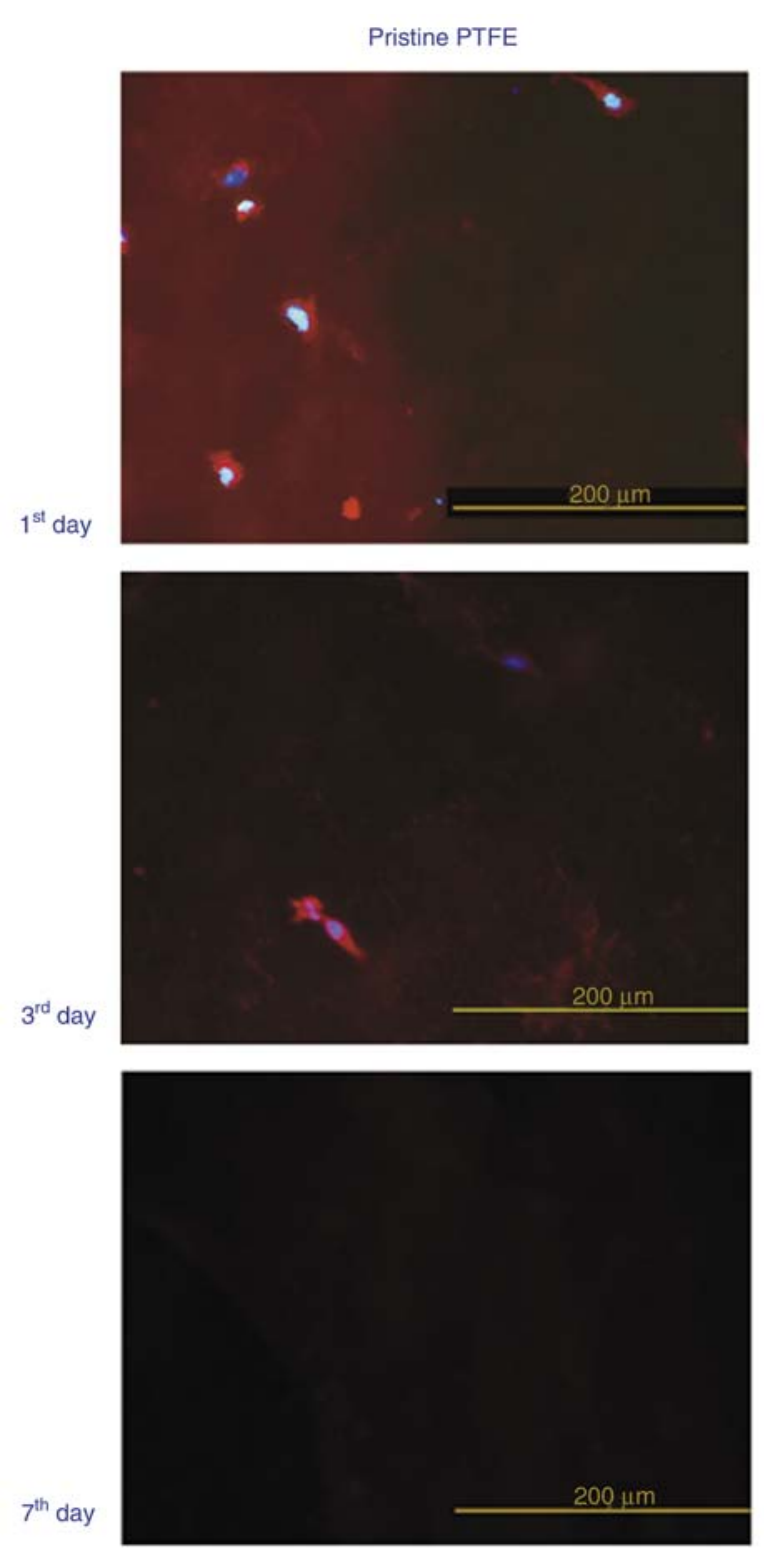

PTFE/plasma
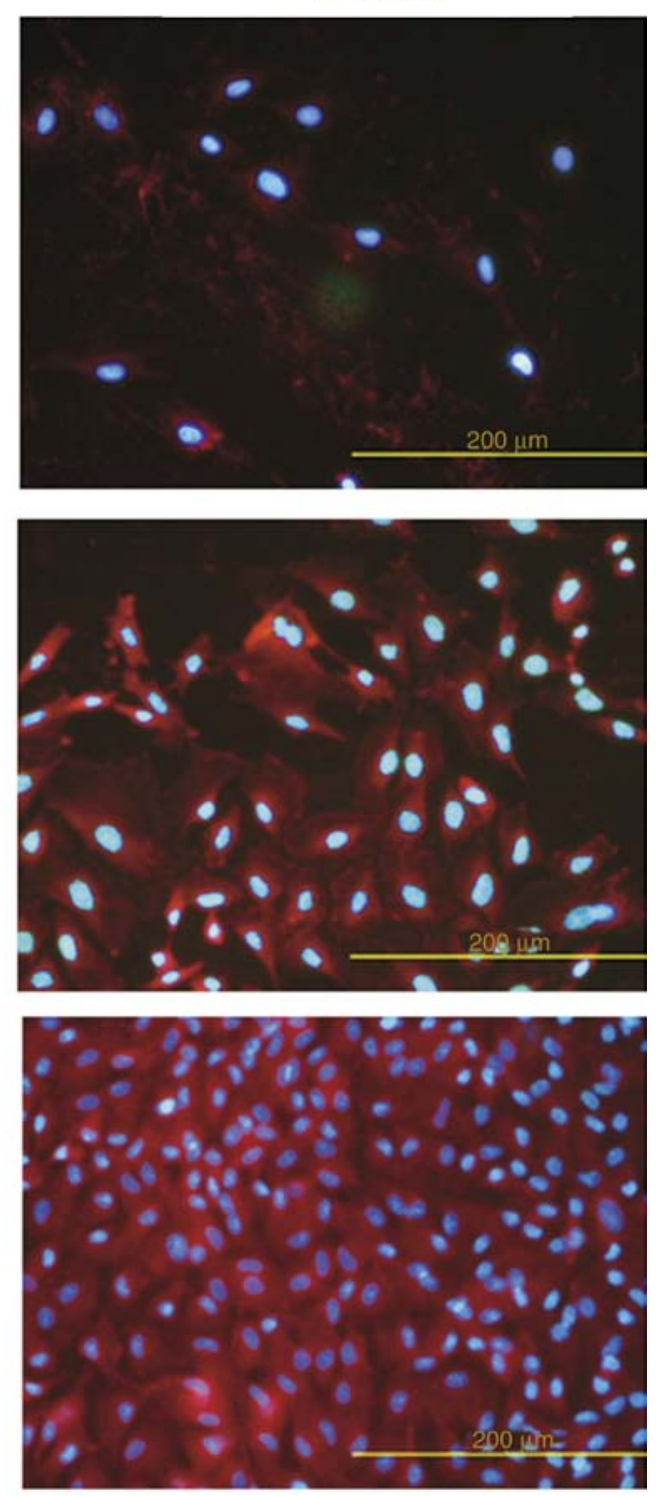

Figure 6. Photographs of adhered and proliferated VSMC cells on the $1^{\text {st }}, 3^{\text {rd }}$ and $7^{\text {th }}$ day from seeding on PTFE modified with $5 \mathrm{~W}$ and $240 \mathrm{~s}$

\section{References}

[1] Øiseth S. K., Krozer A., Kasemo B., Lausmaa J.: Surface modification of spin-coated high-density polyethylene films by argon and oxygen glow discharge plasma treatments. Applied Surface Science, 202, 92-103 (2002).

DOI: 10.1016/S0169-4332(02)00928-5

[2] Hegemann D., Brunner H., Oehr C.: Plasma treatment of polymers for surface and adhesion improvement. Nuclear Instruments and Methods in Physics Research Section B: Beam Interactions with Materials and Atoms, 208, 281-286 (2003). DOI: $10.1016 / \mathrm{S} 0168-583 \mathrm{X}(03) 00644-\mathrm{X}$
[3] Švorčík V., Kasálková N., Slepička P., Záruba K., Král V., Bačáková L., Pařízek M., Lisá V., Ruml T., Gbelcová H., Rimpelová S., Macková A.: Cytocompatibility of $\mathrm{Ar}^{+}$plasma treated and $\mathrm{Au}$ nanoparticle-grafted PE. Nuclear Instruments and Methods in Physics Research Section B: Beam Interactions with Materials and Atoms, 267, 1904-1910 (2009).

DOI: $10.1016 /$ j.nimb.2009.03.099

[4] Djurabekova F., Samela J., Timko H., Nordlund K., Calatroni S., Taborelli M., Wuensch W.: Crater formation by single ions, cluster ions and ion 'showers'. Nuclear Instruments and Methods in Physics Research Section B: Beam Interactions with Materials and Atoms, 272, 374-376 (2012).

DOI: $10.1016 / \mathrm{j} . \mathrm{nimb} .2011 .01 .104$ 
[5] Inagaki N., Tasaka S., Shimada S.: Comparative studies on surface modification of poly(ethylene terephthalate) by remote and direct argon plasmas. Journal of Applied Polymer Science, 79, 808-815 (2001).

DOI: $10.1002 / 1097-4628(20010131) 79: 5<808:: A I D-$ $\mathrm{APP} 50>3.0 . \mathrm{CO} ; 2-\mathrm{B}$

[6] Persson H., Yao Y., Klement U., Rychwalski R. W.: A simple way of improving graphite nanoplatelets (GNP) for their incorporation into a polymer matrix. Express Polymer Letters, 6, 142-147 (2012). DOI: $10.3144 /$ expresspolymlett.2012.15

[7] Bazaka K., Jacob M. V., Crawford R. J., Ivanova E. P.: Plasma-assisted surface modification of organic biopolymers to prevent bacterial attachment. Acta Biomaterialia, 7, 2015-2028 (2011).

DOI: $10.1016 /$ j.actbio.2010.12.024

[8] Bisschops T. J., de Hoog F. J.: On the plasmaphysics of plasma-etching. Pure and Applied Chemistry, 57, 13111320 (1985).

DOI: $10.1351 / \mathrm{pac} 198557091311$

[9] Grace J. M., Gerenser L. J.: Plasma treatment of polymers. Journal of Dispersion Science and Technology, 24, 305-341 (2003).

DOI: 10.1081/DIS-120021793

[10] Bačáková L., Mareš V., Bottone M. G., Pellicciari C., Lisá V., Švorčík V.: Fluorine ion-implanted polystyrene improves growth and viability of vascular smooth muscle cells in culture. Journal of Biomedical Materials Research Part A, 49, 369-379 (2000).

DOI: 10.1002/(SICI)1097-4636(20000305)49:3<369:: AID-JBM10>3.0.CO;2-W

[11] Wilson D. J., Williams R. L., Pond R. C.: Plasma modification of PTFE surfaces. Part I: Surfaces immediately following plasma treatment. Surface and Interface Analysis, 31, 385-396 (2001).

DOI: $10.1002 /$ sia. 1065

[12] Kim K. S., Ryu C. M., Park C. S., Sur G. S., Park C. E.: Investigation of crystallinity effects on the surface of oxygen plasma treated low density polyethylene using X-ray photoelectron spectroscopy. Polymer, 44, 6287-6295 (2003).

DOI: 10.1016/S0032-3861(03)00674-8

[13] Kotál V., Švorčík V., Slepička P., Sajdl P., Bláhová O., Šutta P., Hnatowicz V.: Gold coating of poly(ethylene terephthalate) modified by argon plasma. Plasma Processes and Polymers, 4, 69-76 (2007). DOI: 10.1002/ppap.200600069

[14] Kasálková N., Makajová Z., Pařízek M., Slepička P., Kolářová K., Bačáková L., Hnatowicz V., Švorčík V.: Cell adhesion and proliferation on plasma-treated and poly(ethylene glycol)-grafted polyethylene. Journal of Adhesion Science and Technology, 24, 743-754 (2010). DOI: $10.1163 / 016942409 X 12579497420762$

[15] Švorčík V., Řezníčková A., Kolská Z., Slepička P.: Variable surface properties of PTFE foils. e-Polymers, no.133 (2010).
[16] Švorčík V., Chaloupka A., Řezanka P., Slepička P., Kolská Z., Kasálková N., Hubáček T., Siegel J.: Aunanoparticles grafted on plasma treated PE. Radiation Physics and Chemistry, 79, 315-317 (2010). DOI: 10.1016/j.radphyschem.2009.08.036

[17] Grausová L., Vacík J., Vorlicek V., Švorčík V., Slepička P., Bílková P., Vandrovcová M., Lisá V., Bačáková L.: Fullerene $\mathrm{C}_{60}$ films of continuous and micropatterned morphology as substrates for adhesion and growth of bone cells. Diamond and Related Materials, 18, 578-586 (2009).

DOI: 10.1016/j.diamond.2008.10.024

[18] Vandrovcová M., Vacík J., Švorčík V., Slepička P., Kasálková N., Vorlíček V., Lavrentiev V., Voseček V., Grausová L., Lisá V., Bačáková L.: Fullerene $\mathrm{C}_{60}$ and hybrid $\mathrm{C}_{60} / \mathrm{Ti}$ films as substrates for adhesion and growth of bone cells. Physica Status Solidi A, 205, 2252-2261 (2008).

DOI: $10.1002 /$ pssa.200879730

[19] Borcia G., Chiper A., Rusu I.: Using a $\mathrm{He}+\mathrm{N}_{2}$ dielectric barrier discharge for the modification of polymer surface properties. Plasma Sources Science and Technology, 15, 849-857 (2006).

DOI: $10.1088 / 0963-0252 / 15 / 4 / 031$

[20] De Geyter N., Morent R., Leys C., Gengembre L., Payen E., Van Vlierberghe S., Schacht S.: DBD treatment of polyethylene terephthalate: Atmospheric versus medium pressure treatment. Surface and Coatings Technology, 202, 3000-3010 (2008).

DOI: $10.1016 / j$.surfcoat.2007.11.001

[21] De Geyter N., Morent R., Leys C., Gengembre L., Payen E.: Treatment of polymer films with a dielectric barrier discharge in air, helium and argon at medium pressure. Surface and Coatings Technology, 201, 70667075 (2007).

DOI: 10.1016/j.surfcoat.2007.01.008

[22] Borcia G., Anderson C. A., Brown N. M. D.: Using a nitrogen dielectric barrier discharge for surface treatment. Plasma Sources Science and Technology, 14, 259-267 (2005).

DOI: $10.1088 / 0963-0252 / 14 / 2 / 006$

[23] Kim M. S., Khang G., Lee H. B.: Gradient polymer surfaces for biomedical applications. Progress in Polymer Science, 33, 138-164 (2008). DOI: 10.1016/j.progpolymsci.2007.06.001

[24] Tian H., Tang Y., Zhuang X., Chen X., Jing X.: Biodegradable synthetic polymers: Preparation, functionalization and biomedical application. Progress in Polymer Science, 37, 237-280 (2012).

DOI: $10.1016 /$ j.progpolymsci.2011.06.004

[25] Goddard J. M., Hotchkiss J. H.: Polymer surface modification for the attachment of bioactive compounds. Progress in Polymer Science, 32, 698-725 (2007). DOI: $10.1016 / \mathrm{j}$. progpolymsci.2007.04.002 
[26] Synytsya A., Synytsya A., Blafkova P., Ederova J., Spevacek J., Slepicka P., Kral V., Volka V.: pH-controlled self-assembling of meso-tetrakis(4-sulfonatophenyl)porphyrin-chitosan complexes. Biomacromolecules, 10, 1067-1076 (2009).

DOI: $10.1021 / \mathrm{bm} 8011715$

[27] De Geyter N., Morent R., Leys C.: Influence of ambient conditions on the ageing behaviour of plasmatreated PET surfaces. Nuclear Instruments and Methods in Physics Research Section B: Beam Interactions with Materials and Atoms B, 266, 3086-3090 (2008). DOI: 10.1016/j.nimb.2008.03.167
[28] Wilson D. J., Williams R. L., Pond R. C.: Plasma modification of PTFE surfaces. Part II: Plasma-treated surfaces following storage in air or PBS. Surface and Interface Analysis, 31, 397-408 (2001).

DOI: $10.1002 /$ sia.1066 